\title{
A Renewed Approach to the ABC Landscape Assessment Method: An Application to Muntanyes d'Ordal, Barcelona Metropolitan Area
}

\author{
David Serrano Giné* \\ University Rovira i Virgili, Department of Geography, Joanot Martorell, 15; 43480 Vila-seca, Spain
}

\begin{abstract}
The aim of this paper is to describe a renewed approach to the $A B C$ landscape assessment method, a procedure that undertakes landscape approach considering abiotic (A), biotic (B) and cultural (C) elements shaping the landscape. This new method is organized in three nested multi-scaled levels defined with high accuracy $(1: 10,000 ; 1: 20,000 ; 1: 25,000)$, it combines holistic and parametric approaches and it delineates landscape units from both a typological and chorological point of view. The procedure is based on field work, congruently integrates physical, cultural and perceived landscape components and focuses on the spatial dimension of landscape. Landscape units are hierarchised and classified, leading to a landscape taxonomy. An example is given for Muntanyes d'Ordal, in the Barcelona metropolitan area, with 36 units and 1,019 delineations at Level I, 8 units and 74 delineations at Level II and 14 units at Level III. Overall, 42.5\% of Level I delineations are defined by biotic elements and $32.4 \%$ by anthropic elements, which shows the peri-urban nature of the area studied. The main interest and originality of the method lies in the fact that the holistic and parametric approaches are integrated using a systematic procedure that can be easily replicated anywhere so that results from different areas can be compared.
\end{abstract}

\section{Keywords:}

Landscape, landscape method, landscape chorology, landscape taxonomy, Muntanyes d'Ordal

*Corresponding author. Email: david.serrano@urv.cat

(C) The Authors. 2018. Landscape Online. This is an Open Access article distributed under the terms of the Creative Commons Attribution License (http://creativecommons.org/licenses/by/4.0), which permits unrestricted use, distribution, and reproduction in any medium, provided the original work is properly cited. 


\section{Introduction}

\subsection{Motivation}

The European Landscape Convention (ELC, Council of Europe 2000) promotes the study and protection of European landscapes and encourages its member states to identify, describe and characterize the landscapes within their boundaries. ELC does not propose principles or procedures for tackling landscape research, and a number of landscape approaches have appeared in recent years to fill this methodological gap (Brunetta \& Voghera 2008). Because of the variety of objectives and interests, there are also a variety of approaches to the study of the landscape; this heterogeneity can be seen in a number of ways such as how the landscape units are delineated or how landscape cartography is performed (Vallés et al. 2012; Balestrieri 2015).

There are two main approaches to classifying and characterising landscapes, depending on whether the focus is on landscape chorology or on landscape typology. Landscape chorology consists of unique landscape regions of a particular nature or identity. It uses a number of natural and social components and pays particular attention to perceived issues. Chorological studies commonly use a holistic method, although this method is not exclusive to this approach (Rougerie \& Beroutchachili 1991). Landscape typology systematically classifies landscape by considering generic types that can occur in different places (Zonneveld 1994). It takes components such as morphology, vegetation or settlement patterns and combines them to define particular relationships. Although it is not exclusive to this approach, parametric methods are commonly used (Mitchell 1991).

Despite the fact that heterogeneity is common, in the European context there are two main procedures: Landscape Character Assessment (LCA) and LANMAP. The former adopts a chorological approach and a holistic method and the latter a typological approach and a parametric method. The LCA has been in widespread use in a variety of countries and regions, and has steered landscape studies to an understanding of the landscape that has become quite common (Swanwick 2002; Tudor 2014). The procedure is understood to be the most comprehensive, at least at the European level (Wascher 2005), and its main distinguishing feature is that it delineates landscape units that include physical, cultural and perceived items. However, it has been suggested that these elements are not treated rigorously (Griffiths 2004), and some reviews have pointed out that the scale of analysis is not always what it should be. So, various weaknesses have been reported and some suggestions have been made for improvement (Vallés et al. 2012; Van Eetvelde \& Antrop 2009). A different approach consists of parametric procedures, according to Mitchell's (1991) classification. The LANMAP methodology (Mücher et al. 2010) considers a set of criteria related to climate, topography, parent material and land cover to delineate landscape units using an ecophysical approach. Its main characteristic is that it is objective and consistent, and it distinguishes and names hierarchical levels on a given scale. On the other hand, it gives no cultural, historical or socioeconomic information and neither does it consider perceived values (Mücher et al. 2003). From a spatial point of view, the landscape approach provides a final map at a scale of $\pm 1.2 \mathrm{M}$ (a minimum mapping unit of $\left.11 \mathrm{~km}^{2}\right)$, which allows a full pan European scope but makes it difficult to zoom in at the regional level, so it may underestimate local and regional landscape differences (Mezősi et al. 2016).

The main differences between LCA and LANMAP are that LCA regards every delineation as unique whereas LANMAP looks for similarities and consistency in classifying landscape units. LANMAP makes a classification of several hierarchical levels and LCA focuses on perception issues and local identity. It is difficult to make deeper comparisons because the scale, methods and techniques of landscape approaches vary greatly, and meaningful conclusions are hard to generalise.

\subsection{Goals of the study}

The aim of this paper is to introduce a new landscape method that merges the two main approaches existing to classifying and characterising landscapes. 
In this paper we present a renewed approach to the ABC landscape method (Bolòs 1992; Botequilha Leitão et al. 2006); this new approach uses landscape typology and landscape chorology, and parametric and holistic approaches in a stepwise procedure organised in three scale stages.

The $A B C$ method is a seminal but largely unknown landscape procedure that takes its name from the contribution of the elements shaping the landscape: A for abiotic, B for biotic and C for cultural. Originally, this is a typological procedure based both on a holistic and parametric basis, and the renewed approach includes chorological criteria in a multiscale classification, making the $A B C$ approach a complete and attractive landscape procedure.

In section two of this paper the $A B C$ method is briefly introduced and, subsequently, the renewed approach is described in detail. In section three a case study undertaken in Muntanyes d'Ordal, Barcelona metropolitan area, is introduced, and in section four quantitative and qualitative results are reported, including a cartographic description on different scales. Finally, the main contributions of the procedure are discussed.

\section{Method}

\subsection{The ABC method}

The $A B C$ method was initially introduced by Bolòs (1992) as a way of classifying landscapes by their main components. This classification is based on an analysis of the landscape's predominant elements and the dynamics they generate. The procedure assumes that any given landscape consists of the interaction of abiotic, biotic and anthropic or cultural elements, which combine with one another to varying degrees. The predominance of one element over the others, and even the absence of an element makes a typological classification of the landscape possible that conceives an open range of landscape types. The procedure is parametric (it focuses on the main components) and holistic (it focuses on landscape dynamics). Since this conception of landscape is spatial, predominance is established on a spatial basis (i.e. occupied surface). Units of landscape are delineated by their main components and subsequent dynamics, and they are distinguished by analysing the changes in components, predominance and dynamics (Dollfus 1970). A landscape is classified by combining the initial letter of the main components (A for abiotic, $B$ for biotic, and $C$ for cultural) in a given order depending on the importance they have within the landscape itself. A predominance of over $50 \%$ (principal predominance) is shown in capital letters, a predominance between $50 \%$ and $20 \%$ (secondary predominance) is shown in lower case letters, and a predominance of less than 20\% (significant presence) is shown in italic lower case letters. If there is an interdependence of components, which usually occurs when human activity is involved, upper case letters are used between brackets [(CB)]. Finally, sub-indices may be used to refer to specific elements: e.g. $B$ refers to biotic predominance, $B_{1}$ forest predominance, $B_{2}$ bush predominance, $B_{3}$ grass predominance, and so forth (Bolòs \& Bofarull 2007). In a didactic application of this procedure geometric shapes are associated to abiotic, biotic and cultural elements, and a landscape is described by using a simple combination of shapes and sizes that is easy to understand (Figure 1). Botequilha Leitão et al. (2006) reported a number of applications in spatial planning and suggested a new name for the procedure.

Despite being a seminal procedure (Bolòs 1992) easy to implement, the $A B C$ method in general is not a well-known or often used approach. According to Bolòs \& Bofarull (2007) this is because it is highly time-consuming as calls for a close inspection of the elements and dynamics shaping the landscape. A very few examples for this procedure can be recalled (Botequilha Leitão et al. 2006); probably the most distinguished of them is the one performed in the Principality of Andorra (https://www.cartografia.ad/ geoportal; latest access: 17/02/2018), in the heart of the Pyrenees, because gives an utmost example of mountain landscape classification. 


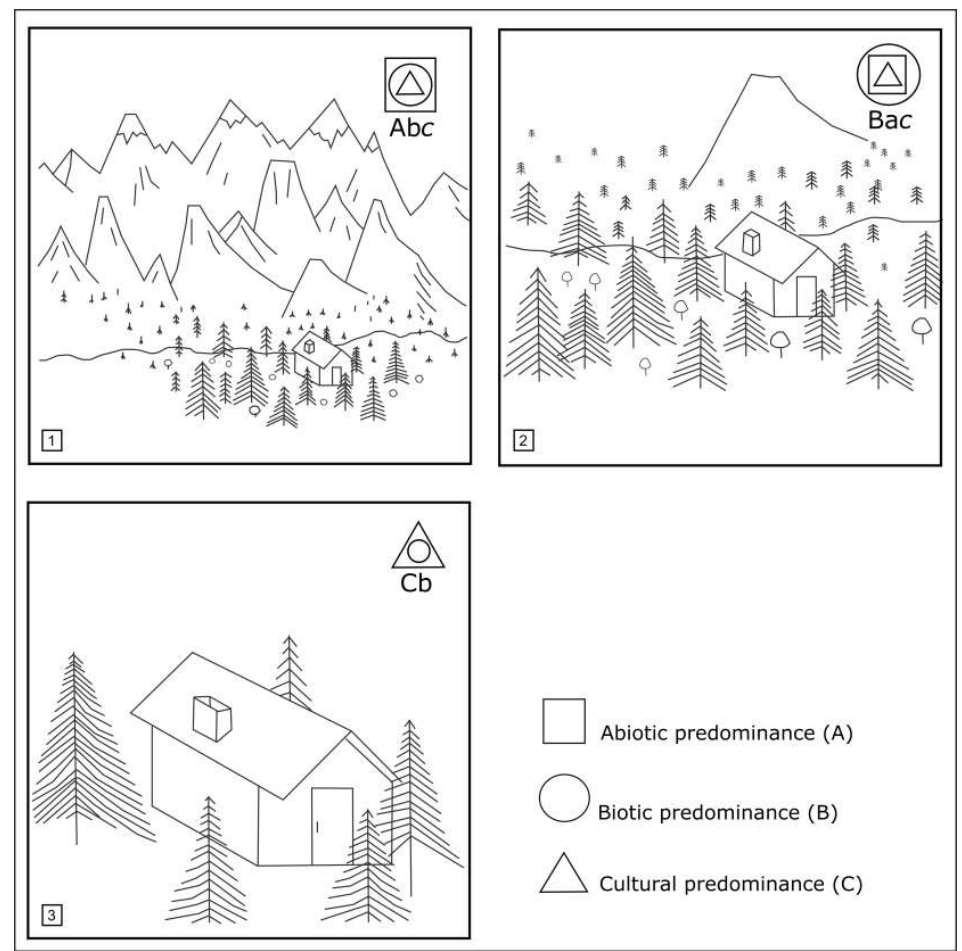

Figure 1: One didactic application for the $A B C$ method uses shapes and letters to characterise the landscape through its main components: A stands for abiotic predominance of elements and it is represented by a square, B stands for biotic and it is represented by a circle, and C for cultural and by a triangle; principal predominance $(>50 \%)$ is shown in capital letters, secondary predominance $(50 \%-20 \%)$ in lower case letters, and significant presence $(<20 \%)$ in italics. In 1 a landscape is represented at a broad scale and the abiotic predominance is main, followed by biotic and a bit of cultural (Abc); in 2 the same landscape is shown at a medium scale, and at this level biotic elements are predominant followed by cultural ones and a significant abiotic presence (Bac); in 3 a view of the same landscape is shown at a detailed level, and cultural elements are predominant followed by biotic whereas abiotic elements are negligible (Cb). Source: modified from Bolòs (1992).

\subsection{The renewed $A B C$ approach}

The $A B C$ method was renewed by combining landscape typology and landscape chorology, and holistic and parametric approaches on three scales of analysis. Figure 2 gives an overview of the method. At each of the three levels a particular scale is used to characterise, describe and map landscape units with criteria that are adapted to each spatial approach. The first scale level $(1: 10,000)$ is very detailed and defines landscape units using landscape typology and a parametric procedure, even though it adopts a highly detailed holistic approach. The second level $(1: 20,000)$ includes the first level delineations and so is less accurate; at this level landscape units are delineated using a parametric procedure and visual indicators and the general approach is holistic. At the third level $(1: 25,000)$, accuracy is lower but geographical meaning is greater since landscape units are defined by chorology using only a holistic procedure. These three levels are hierarchical: the first is contained in the second, and the second in the third, forming a series of nested levels. Because this hierarchy is also a classification, the result is a landscape taxonomy.

The renewed $A B C$ landscape approach was set up in three steps, each step belonging to a given scale level and to a given landscape rationale, and is conceived in three nested levels which are hierarchical both in their meaning and spatial sense. The whole procedure uses typological, chorological, parametric and holistic approaches, but in different ways according to each level of the procedure. The first Level uses typology and parametric criteria, from a holistic point of view and belongs to the originally $A B C$ method; Level I is the basis of the landscape approach, and its goal is to define landscape types. 


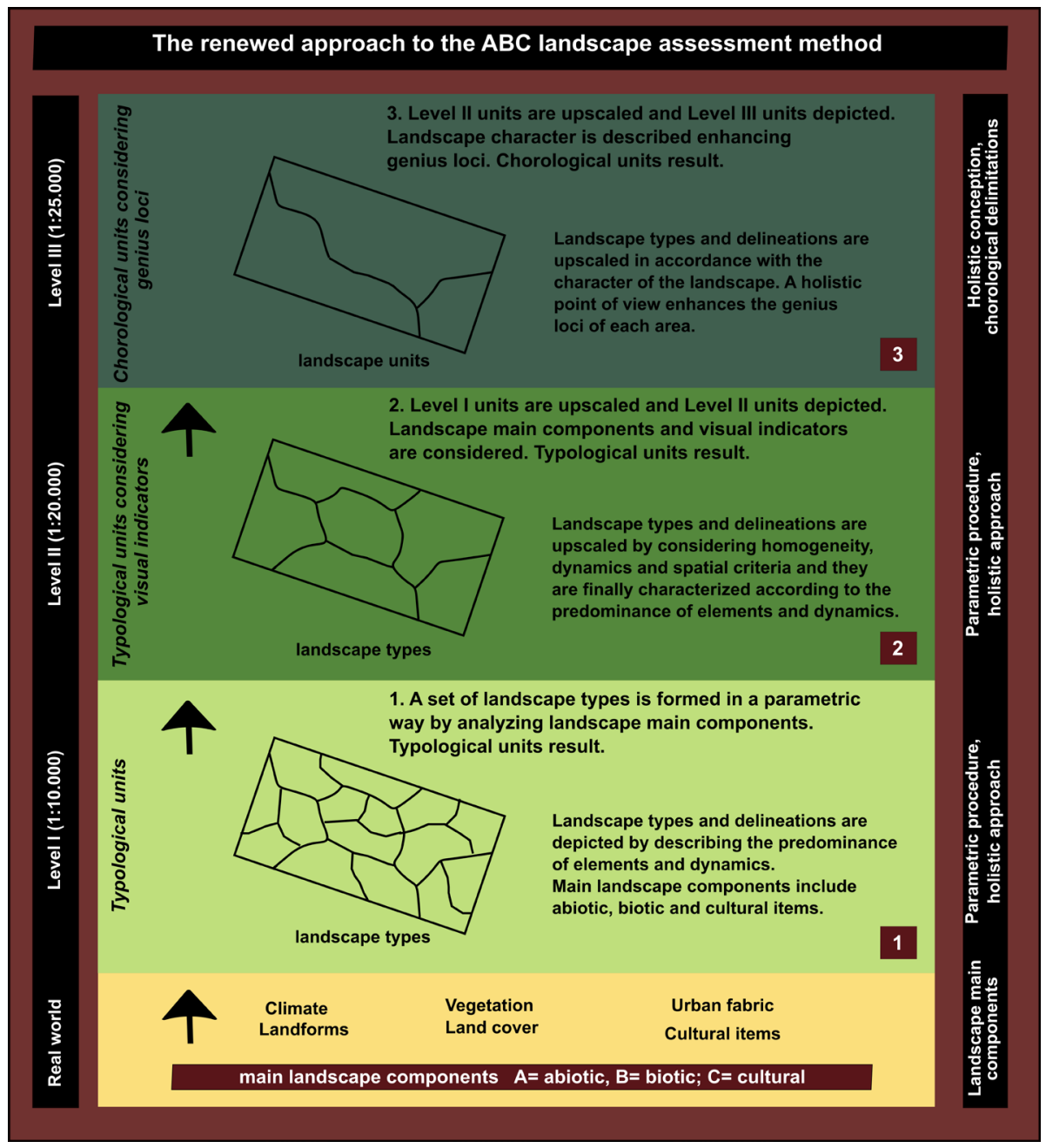

Figure 2: Overview of the renewed $\mathrm{ABC}$ approach.

The second Level updates the same criteria to a medium scale and includes visual indicators that shape genius loci for each place, and its goal is to upscale landscape types to a 1:20,000 scale. The third Level uses chorological and holistic approaches to upscale Level II delimitations, provides a general overview of the studied landscape at a broad scale, and gives an approach of the landscape character at a 1:25,000 scale. Both second and third levels belong solely to the renewed $A B C$ approach.

\subsubsection{Level I: defining landscape types}

Level I landscape units are the basis of the taxonomy. The scale used is 1:10,000, which is a very accurate scale that delineates highly homogeneous landscape units so relatively small pieces of land with similar characteristics and similar dynamics can be differentiated. They are depicted by describing the predominance of elements and dynamics (i.e. degraded scrubland on a steep slope) and since typologies and parametric criteria are used, a particular classification may exist more than once in a number of locations. Landscape elements are physical items (e.g. landforms, soil, vegetation and so forth) and social items (e.g. cultures, urban fabrics, heritage sites, and so forth) and they are combined in the same way as they shape the landscape, which is why this classification must not be mistaken for land cover or land use. GIS software helps to manage the related databases and to visualize them on a map. The accuracy of this level requires the data to be highly detailed and field work is usually necessary. The main goal of the level is to highlight landscape structure by showing its main elements and dynamics as accurately as possible because Level I delineations are the lowest taxonomical level and all upper delimitations rely on them. 


\subsubsection{Level II: upscaling landscape types}

Level II landscape units are accurate at a scale of 1:20,000 and the Level I units are generalized. Level I units are upscaled to Level II units by considering homogeneity, dynamics and spatial criteria at $1: 20,000$, and they are finally characterized according to the predominance of elements and dynamics, as in Level I units, but on a different scale. The criterion used to do this takes into account the sense of place and is applied by following a quantitative and qualitative procedure that combines the number and type of Level I units with their meaning in the surrounding landscape (Table 1). Particular attention is paid to visual indicators such as coherence, imageability or complexity (Tveit et al 2006) because they shape genius loci. This user-supervised method gives better results than any geomatic procedure, although it can be supplemented by just such a procedure. The purpose of this hierarchical level is to assemble landscape Level I delineations that share common features on a given scale in a given area, so that spatial sense is enhanced at 1:20,000.

Table 1: Criteria used to generalize Level I landscape units $(1: 10,000)$ to Level II landscape units $(1: 20,000)$

\begin{tabular}{|l|l|}
\hline Criterion & Acronym \\
\hline Most frequent landscape Level I unit & FRQ \\
\hline Biggest Level I unit & BG \\
\hline Other significant level I units fewer in number or size & SGT \\
\hline Total account of delineations and their general meaning & TOT \\
\hline General landscape character in the area & LPCH \\
\hline Visual indicators & VIN \\
\hline
\end{tabular}

\subsubsection{Level III: defining landscape character}

Level III landscape units are accurate at a scale of 1:25,000 and are formed by grouping Level II delineations. They are of considerable geographical interest since they are described in accordance with the character of a landscape and from a holistic point of view that synthesizes Level II units and enhances the genius loci of each area. Chorological units are delineated by focusing on visual indicators (Tveit et al. 2006), although the area considered is broader than in Level II delineations. In consequence, Level III landscape units are made up by using typology and parametric criteria (by aggregating Landscape Il units) and landscape chorology and holistic approaches (describing the character of the landscape); the result is a set of landscape delimitations which can be considered as the LCA procedure understands landscape units.

\section{Study area}

The renewed approach to the $A B C$ method was tested in Muntanyes d'Ordal, a 15,000 $\mathrm{Ha}$ area in Barcelona metropolitan area (Figure 3). Muntanyes d'Ordal landscape is characterized by rough topography and Mediterranean shrubs and forests; although the area has a large number of low-density housing developments and industrialised areas, it also has interesting landscape values (Serrano, 2014) and is partially protected by the Nature 2000 Network. Over 145.000 inhabitants scattered in twelve urban settlements and more than 30 housing developments give a population density of 967.6 inhabitants $/ \mathrm{km} 2$ which provides the area with a peri-urban character defined by dispersive urban growth, road networks and fragmented landscapes. The study area is of considerable interest from a planning point of view; it was chosen because its periurban character and the fact of being representative of Barcelona metropolitan area landscape.

\section{Results}

Level I consists of 36 landscape classes distributed into 1,019 delineations (Table 2). Nearly half of the delineations (42.5\%) are biotically dominant and are composed of six main categories; $32.4 \%$ are culturally dominant, with largely low density urban fabric (94 units) in the central region of the area; $7.8 \%$ are abiotically dominant (mainly fluvial 


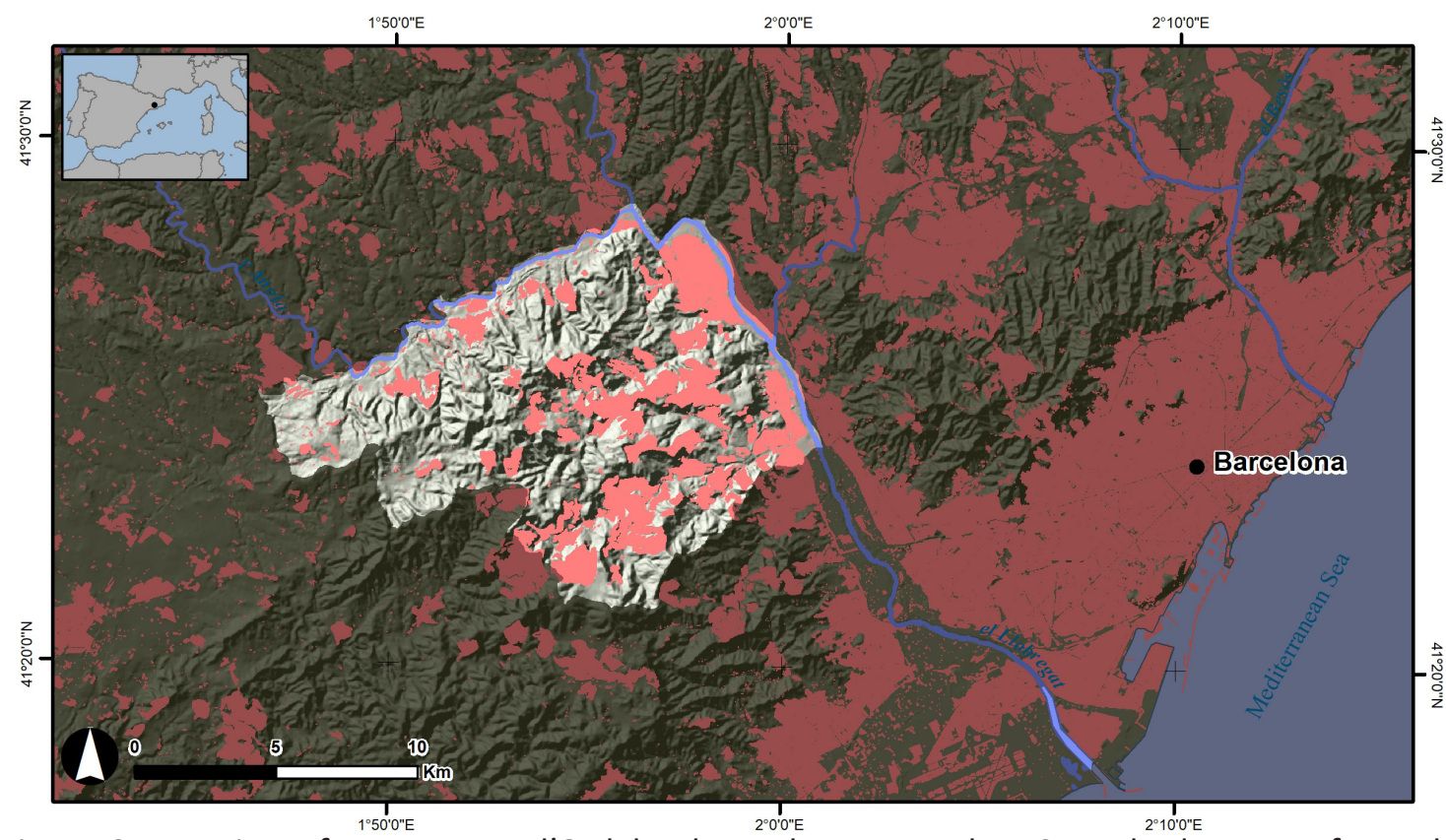

Figure 3: Location of Muntanyes d'Ordal, where the renewed $A B C$ method was performed. Note: built up areas are depicted in pink colour.

landscapes); and units with an interdependence of components are mainly agrarian landscapes (90\%). Acicular forest is the most frequent class (21.7\%) with similar amounts of dense $\left(\mathrm{B}_{111}\right)$ and sparse $\left(\mathrm{B}_{112}\right)$ types and they are mainly distributed in the east and centre of the area studied. Scrubland landscapes occupy nearly $11 \%$ of the landscape units, with subclasses of irregular sizes $\left(B_{22}\right.$ slightly more than $\left.5 \% ; B_{22 a} 2.5 \%\right)$, and landscape units defined by crops and urban developments on slopes (10.7\% each). A large number of landscape units, with 15 landscape classes, covers less than $5 \%$ of the whole area, which shows the homogeneity and fragmentation of the landscape (Figure 4).

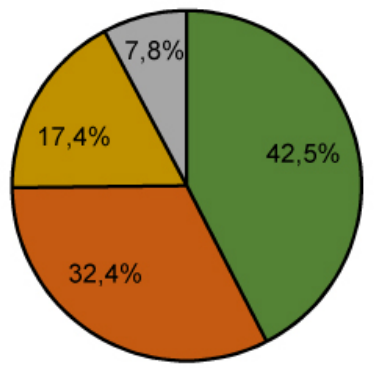

口Biotic predominance

口Anthropic predominance

口More than one predominance $\square$ Abiotic predominance

Figure 4: Overview of Level I landscape classification: predominance of main elements
Level II consists of 8 landscape classes distributed in 74 delineations. A total of $47 \%$ of these delineations are forest units (B11), mainly dense coniferous forests clustered in the central part of the area studied. Scrubland-dominated units represent $11 \%$ of the area and units with an interdependence of components, $15 \%$ (mainly crops on the borders of the area studied). Nevertheless, the most remarkable physiognomic distinction comes from urban sprawldefined units (C2), mainly on medium or steep slopes but also in flat areas, which occupy $9 \%$ of the surface of the studied area but define its character because of their distribution and their physical and cultural meaning.

Level III clusters Level II landscape units in 14 delineations that are defined in terms of the units' structure, dynamics and genesis and they show the landscape's character in terms of its geographical meaning. These units are named for their main features, their geographical location and scale; for example, "Low density housing development on a steep slope" or "Perennial oak forest on a steep siliceous slope". Interestingly, some units are regarded by locals to fully represent the area studied, whereas others are less well-defined and are not regarded as typical of the studied area and so have 
a different landscape character. An overview of the method and the results at each taxonomic level can

\section{be found in Figure 5.}
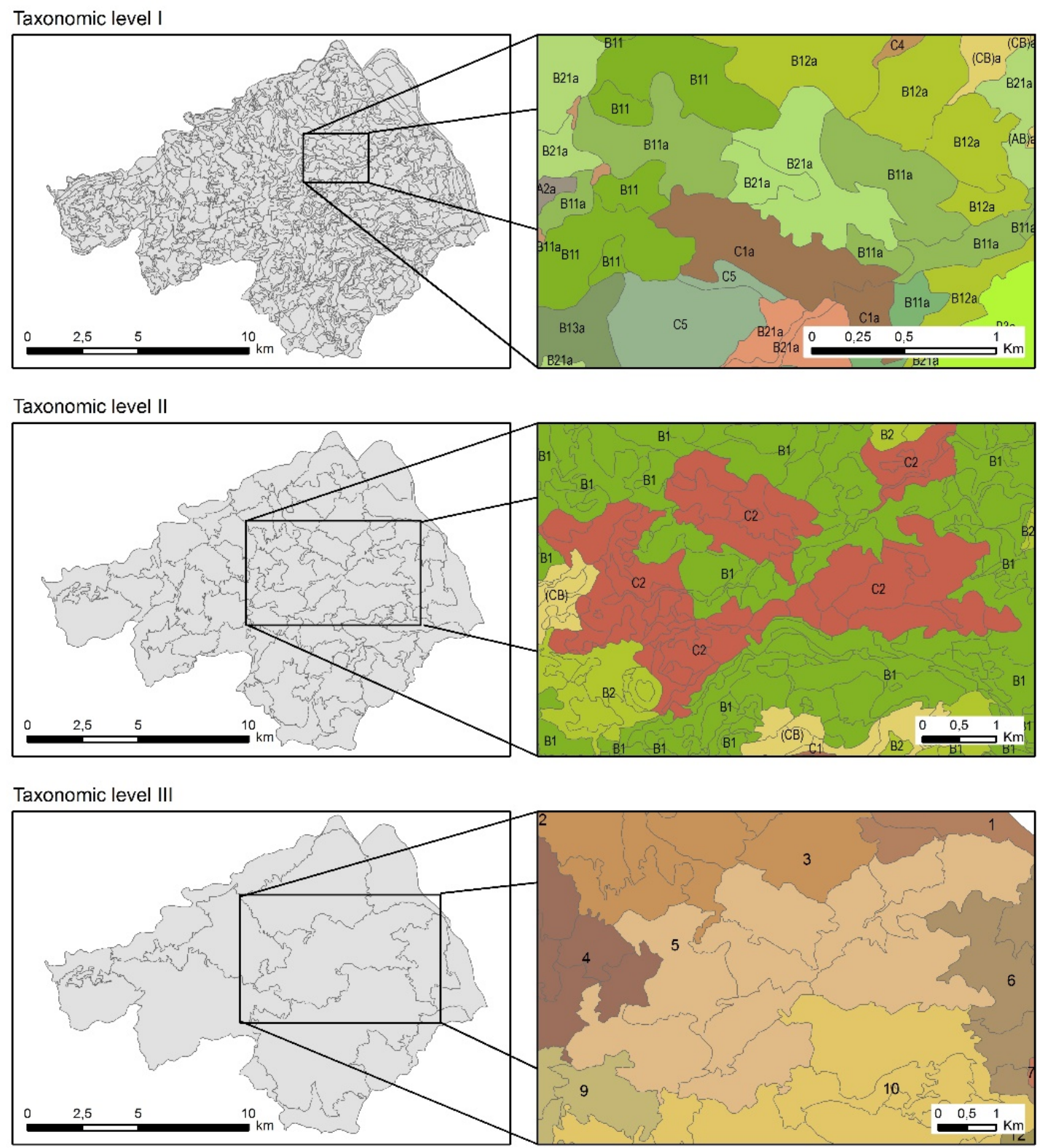

Figure 5: General overview and zoomed detail (roughly the same area at three levels) for each of the three taxonomic levels. Note that Level I delineations are also depicted at Level II, and Level II delineations at Level III.

Table 2: Level I landscape classes. Note: A stands for abiotic predominance of elements; B for biotic; and C for cultural. Principal predominance $(>50 \%)$ is shown in capital letters, secondary predominance $(50 \%-20 \%)$ in lower case letters, and significant presence $(<20 \%)$ in italics.

\begin{tabular}{|l|l|l|l|}
\hline \multicolumn{2}{|l|}{ Abiotic predominance (A) } \\
\hline $\mathbf{A}_{\mathbf{1}}$ & compact rock & & \\
\hline $\mathbf{A}_{\mathbf{2}}$ & loose rock & & \\
\hline $\mathbf{A}_{\mathbf{5}}$ & fresh water & & \\
\hline
\end{tabular}


Table 2: Prosecution

\begin{tabular}{|c|c|c|c|}
\hline \multicolumn{4}{|c|}{ Biotic predominance (B) } \\
\hline \multirow[t]{11}{*}{$\overline{\mathbf{B}_{1}}$} & forest & & \\
\hline & $\mathbf{B}_{11}$ & acicular forest & \\
\hline & & $\mathbf{B}_{111}$ & dense acicular forest \\
\hline & & $\mathbf{B}_{112}$ & sparse acicular forest \\
\hline & & $\mathbf{B}_{112} a$ & $\begin{array}{l}\text { sparse acicular forest in } \\
\text { slope }\end{array}$ \\
\hline & $\mathbf{B}_{12}$ & deciduous forest & \\
\hline & & $\mathbf{B}_{121}$ & dense deciduous forest \\
\hline & & $\mathbf{B}_{122}$ & sparse deciduous forest \\
\hline & $\mathbf{B}_{13}$ & Mediterranean perennial forest & \\
\hline & & $\mathbf{B}_{131}$ & $\begin{array}{l}\text { dense Mediterranean } \\
\text { perennial forest }\end{array}$ \\
\hline & & $\mathbf{B}_{132}$ & $\begin{array}{l}\text { sparse Mediterranean } \\
\text { perennial forest }\end{array}$ \\
\hline \multirow[t]{4}{*}{$\mathbf{B}_{2}$} & scrubland & & \\
\hline & $\mathbf{B}_{21}$ & dense scrubland & \\
\hline & $\mathbf{B}_{22}$ & sparse scrubland & \\
\hline & $\mathbf{B}_{22} \boldsymbol{a}$ & sparse scrubland in slope & \\
\hline $\mathbf{B}_{3}$ & natural grassland or pasture & & \\
\hline BC & degraded vegetation & & \\
\hline \multicolumn{4}{|c|}{ Cultural predominance (C) } \\
\hline \multirow[t]{4}{*}{$\mathrm{C}_{1}$} & dense urban fabric & & \\
\hline & $\mathrm{C}_{11}$ & dense urban fabric with high buildings & \\
\hline & $\mathrm{C}_{12}$ & dense urban fabric with low buildings & \\
\hline & $\mathbf{C}_{13}$ & dense urban fabric with buildings of mixed & \\
\hline \multirow[t]{2}{*}{$\mathrm{C}_{2}$} & low density urban fabric & & \\
\hline & $\mathrm{C}_{2} a$ & low density urban fabric in slope & \\
\hline $\mathrm{C}_{3}$ & shopping centre & & \\
\hline $\mathbf{C}_{4}$ & infrastructure & & \\
\hline $\mathrm{C}_{5}$ & industrial estate & & \\
\hline $\mathrm{C}_{6}$ & sports complex & & \\
\hline \multirow[t]{2}{*}{$\mathbf{C A}$} & mining & & \\
\hline & $\mathrm{CA}_{2}$ & quarry & \\
\hline \multicolumn{4}{|c|}{ Interdependence of components } \\
\hline (CA5) & marsh & & \\
\hline \multirow[t]{6}{*}{ (CB) } & cropland & & \\
\hline & $\left(\mathrm{CB}_{1}\right)$ & non-irrigated tree crop & \\
\hline & $\left(\mathrm{CB}_{2}\right)$ & non-irrigated brush crop & \\
\hline & $\left(\mathrm{CB}_{1}\right) a_{5}$ & irrigated tree crop & \\
\hline & $\left(\mathrm{CB}_{123}\right) a_{5}$ & irrigated vegetable garden & \\
\hline & $\mathrm{C}_{3}(\mathrm{CB}) a_{5}$ & golf course, garden & \\
\hline$\left(\mathrm{A}_{2} \mathrm{C}\right)$ & derelict mine & & \\
\hline (Bc) & neglected cropland & & \\
\hline (Bc) $a$ & neglected cropland on a slope & & \\
\hline
\end{tabular}




\section{Discussion}

The renewed $A B C$ approach combines holistic and parametric methods and chorological and typological delineations in a set of three nested scales that involves three spatial approaches. Holistic and parametric methods have pros and cons and their combination is understood to be enriching when undertaking comprehensive approaches although their combined used is not common (Van Eetvelde \& Antrop 2009). Many procedures are based on holistic premises (Balestrieri 2015), and most of them involve using expert knowledge (Wascher 2005). Although these methods are common in classical land evaluation procedures (Zonneveld 1994), they are frequently criticized for being inconsistent or inaccurate (Griffiths 2004). As Vallés et al. (2012) pointed out, there are a large number of landscape methods and classifications and this can pose a problem when landscape units conceived from different approaches are compared. So some attempt at harmonization is required if different landscapes are to be compared. The combination of holistic and parametric procedures in a single landscape approach should be regarded as a bridge procedure, and the renewed $A B C$ approach might play an important role.

LCA-based procedures delineate unique and individual geographical areas that, if disaggregated, are usually established in a top-down manner (Tudor 2014). However, this means that it is difficult to compare landscape units in different areas, and it is also inaccurate. The fact that small units are defined by large units means that the criteria used to delineate landscape units on the broad scale are transferred to the detailed scale, and the scale factor involves a loss of accuracy (Slocum et al. 2014). The renewed $A B C$ approach avoids this loss of accuracy by scaling up landscape units in a bottom-up way so that large units are defined by small units using a given scale. No loss of accuracy is reported during the upscaling process. Although in different contexts, other landscape methods use a bottom-up approach (Bastian 2000) which is considered to be appropriate and beneficial (Bolòs 1992).
Landscape analysis at different scales is often regarded as a desirable procedure in the landscape approach (Mitchell 1991) and GIS tools are often used (Bastian 2000; Jongman et al. 2006). However, a close inspection of these geomatic procedures reveals that expert knowledge is frequently required at a certain stage of the research (Drăguţ \& Eisank 2012; Vacca et al. 2014) because a number of technical issues appear when GIS layers are combined such as sliver polygons, non-representative units, units below the minimum mapping unit, and so forth (Mücher et al. 2010). The renewed ABC approach undertakes landscape upscaling using quantitative and qualitative procedures and combining holistic and parametric information. For Level I and II, upscaling is done in a set of given landscape classes defined by the main landscape components, so the classification matches the real world and provides a typology of landscapes that is easy to replicate, and hence to compare in different areas. The fact that the landscape classes come from the reality to be classified means that the classification is systematic and minimizes any possible inconsistency when classifying and describing landscape units. Moreover, the upscaling from Level I to Level II units maintains the parametric classification albeit adjusted to a smaller scale. This facet of the method is important because other land classifications operate with closed hierarchical typologies that are not flexible (e.g. CORINE, LANMAP) and can only be adapted to different realities with difficulty, which makes highlighting regional differences or singularities problematical (Mezősi et al. 2016).

A multi-scale approach is regarded as useful for understanding the landscape as a whole (Bolòs 1992), especially when the upscaling is stepwise and nested (Van Eetvelde \& Antrop 2009). It appears that parametric procedures (e.g. LANMAP) pay more attention to it than holistic ones; for instance, the Landscape Catalogues for Catalonia focus on the scale of 1:50.000. According to Drăguţ \& Eisank (2012) three levels of analysis provide a meaningful classification because they decompose complexity and make reality easy to understand, especially at the local/regional level $(1: 10,000-1: 25,000)$. One interesting point about this method is that the 
upscaling process defines the next immediately higher level in the taxonomy using the same criteria for defining the landscape units themselves, so the clustering of landscape units is consistent with the procedure followed and there is no need to deploy cluster analysis to generalize landscape units (Jongman et al. 2006), which makes the procedure easier. Moreover, each level is designed by focusing on a different landscape dimension which makes the procedure more versatile and interesting because it adopts a cartographic and also a thematic point of view.

The method proposed here integrates physical, cultural and perceived landscape components, in an approach that consists of three nested levels. Geographical values can also be highlighted (for example, by using place names to define Level III units) and extra features such as information on archaeological or perceived items can be given to describe and characterize the units, in order to achieve a sense of place. The originality of the method lies in the multi-scaled combination of holistic and parametric procedures and typological and chorological delineations, and is in agreement with the mainstream landscape approaches used these days.

\section{Conclusions}

The landscape approach can be systematically implemented using the renewed $A B C$ approach, a procedure that combines parametric and holistic approaches with a strong spatial sense. The approach is structured in three stepwise scale stages: the first is parametric in design and holistic in understanding, it is conceived at the very accurate scale of $1: 10,000$ and relies on landscape typology; the second is a generalization of the first, and focuses on both landscape typology and landscape chorology using visual indicators at the scale of 1:20,000; the third upscales the second stage, is holistically conceived and generates landscape units on a chorological basis, at a scale of $1: 25,000$. These three analysis levels are nested and since the resulting hierarchy is also a classification, the result is a landscape taxonomy.

This method should be regarded as a bridge procedure between holistic and parametric approaches because it is made by both procedures and provides landscape delineations either typological and chorological at a given scale. This procedure is especially suited for accurate landscape studies (1:10,000-1:25,000) and the three nested levels that define it are particularly good for works with a spatial scope. Besides, this approach provides a landscape taxonomy easy to implement allowing different landscapes to be compared. Consequently, the $A B C$ renewed approach not only does introduce a new procedure to landscape assessment but also it helps to harmonize the current methodological panorama.

In this paper, the procedure was applied for Muntanyes d'Ordal, in the Barcelona metropolitan area, and resulted in a complete landscape approach that can be used at different scale levels. The analysis focuses on physical, social and perceived data and can be used for a number of purposes such as urban planning, environmental management or spatial analysis. Also, landscape hierarchy permits a multidimensional approach and it can be used in any survey or land analysis. The approach presented in this paper can be applied in other areas using the same scale of analysis for each level or an equivalent one, depending on the reality studied.

\section{Acknowledgment}

This study has been carried out within the framework of the SPATIUM project funded by the Spanish Ministry of Economy and Competitiveness under contract number CSO2014-52721-P. 


\section{References}

Balestrieri, M. 2015. Theories and Methods of Rural Landscape Classification in Europe: The Italian Approach. International Journal of Rural Management 11, 2, 156-174. DOI: 10.1177/0973005215604932.

Bastian, O. 2000. Landscape classification in Saxony (Germany) - a tool for holistic regional planning. Landscape and Urban Planning 50, 145-155. DOI:10.1016/S0169-2046(00)00086-4

Bolòs, M. 1992. Manual de ciencia del paisaje. Masson- Barcelona.

Bolòs, M. \& Bofarull, J. 2007. Els mapes d'unitats de paisatge. Proceedings of the 1stNational Seminar on landscape in Andorra, Andorra la Vella, 4-5 June 2007. European Spatial Planning and Landscape 85. Strasbourg: Council of Europe. https://rm.coe. int/16802fc531 (Date: 17/02/2018).

Botequilha Leitão, A.; Miller, J. ; Ahern, J. \& McGarigal, K. 2006. Measuring landscapes. Island Press-Washington.

Brunetta, G. \& Voghera, A. 2008. Evaluating Landscape for Shared Values: Tools, Principles, and Methods. Landscape Research 33, 71-87. DOI: 10.1080/01426390701773839.

Council of Europe 2000. European Landscape Convention and Explanatory Report. Council of Europe. https://rm.coe.int/1680080621. (Date:17/02/2018)

Dollfus, O. 1970. L'espace géographique. Presses Universitaires de France-Paris.

Drăguţ, L. \& Eisank, C. 2014. Automated object-based classification of topography from SRTM data. Geomorphology, 141-142, 21-33. DOI: 10.1016/j. geomorph.2011.12.001.
Griffiths, G.; J. Porter; E. Simmons \& Warnock, S. 2004. The living Landscapes Project. Landscape Character and Biodiversity. English Nature Report 475. Peterborough: English Nature. http://publications.naturalengland.org.uk/ publication/61081 (Date: 17/02/2018).

Jongman, R.H.G.; Bunce, R.G.H. ; Metzger, M.J. ; Mu, C.A.; Howard, D.C. \& Mateus, V.L. 2006. Objectives and applications of a statistical environmental stratification of Europe. Landscape Ecology 21, 409-419. DOI: 10.1007/s10980-005-6428-0

Mezősi, G.; Csorba, P.; Bata, T.; Blanka, V. \& Ladányi, Z. 2016. Similarity assessment of natural landscapes based on taxonomic distance. Applied Ecology and Environmental Research 4, 3, 679-693. DOI: 10.15666/aeer/1403_679693

Mitchell, C. 1991. Terrain Evaluation. LongmanLondon.

Mücher, C.; Klijn, J.; Wascher, D. \& Schamine, J. 2010. A new European Landscape Classification (LANMAP): a transparent, flexible and useroriented methodology to distinguish landscapes. Ecological Indicators 10, 87-103. DOI:10.1016/j. ecolind.2009.03.018.

Mücher, C.A; Bunce, R.G.; Klijn, J.A.; Koomen, A.J.; Metzger, A.J. \& Wascher, D.M. 2003. Identification and Characterisation of Environments and landscapes in Europe. Altera rapport 832. Alterra-Wageningen. http://content.alterra.wur. nl/internet/webdocs/internet/geoinformatie/ projects/LANMAP2/publications/Alterrarep832. pdf (Date: 17/02/2018)

Rougerie, G. \& Beroutchachili, N. 1991. Géosystèmes et paysages: bilan et méthodes. Armand ColinParis.

Serrano Giné, D. 2014. Mapping geomorphological values from a landscape perspective. Journal of Maps10, 4, 554-562. DOI: 10.1080/17445647.2014.892035. 
Slocum, T.A.; McMaster, R.B.; Kessler, F.C. \& Howard, H.H. 2014. Thematic Cartography and geovisualization. Essex-Pearson.

Swanwick, C. 2002. Landscape Character Assessment: Guidance for England and Scotland. Edinburgh: Countryside Agency and Scottish Natural Heritage. http://www.snh.org.uk/pdfs/publications/LCA/ LCA.pdf (Date 17/02/2018).

Tudor, C. 2014. An Approach to Landscape Character Assessment. Sheffield: Natural England. https:// www.gov.uk/government/uploads/system/ uploads/attachment_data/file/396192/ landscape-character-assessment.pdf(Date: 17/02/2018).

Tveit, M.; Ode, Å. \& Fry, G. 2006. Key concepts in a framework for analyzing visual landscape character. Landscape research 31, 3, 229-255. DOI:10.1080/01426390600783269.

Vacca, A.; Loddo, S.; Melis, M.T.; Funedda, A.; Puddu, R.; Verona, M.; Fanni, S.; Fantola, F. \& Madrau, A. 2014. A GIS based method for soil mapping in Sardinia, Italy: A geomatic approach. Journal of Environmental Management 138, 87-96. DOI: 10.1016/j.jenvman.2013.11.018

Vallés, M.; Galiana, F. \& Bru, R. 2012. Towards Harmonisation in Landscape Unit Delineation: An Analysis of Spanish Case Studies. Landscape Research 38, 3, 329-346. DOI:10.1080/01426397 .2011.647896.

Van Eetvelde, V. \& Antrop, M. 2009. A stepwise multiscaled landscape typology and characterisation for trans-regional integration, applied on the federal state of Belgium. Landscape and Urban Planning, 91, 160-170. DOI: 10.1016/j. landurbplan.2008.12.008.
Wascher, D.M. 2005. European Landscape Character Areas. Typologies, Cartography and Indicators for the Assessment of Sustainable Landscapes. Alterra Report 1254. http://library.wur.nl/WebQuery/ wurpubs/fulltext/1778 (Date: 17/02/2018).

Zonneveld, I. 1994. Land ecology: an introduction to landscape ecology as a base for land evaluation, land management and conservation. SPB Amsterdam. 